University of Nebraska - Lincoln

DigitalCommons@University of Nebraska - Lincoln

5-13-2002

\title{
A class of boron-rich solid-state neutron detectors
}

B. W. Robertson

University of Nebraska-Lincoln, brobertson1@unl.edu

Shireen Adenwalla

University of Nebraska-Lincoln, sadenwalla1@unl.edu

A. Harken

University of Nebraska-Lincoln

P. Welsch

University of Nebraska-Lincoln

Jennifer I. Brand

University of Nebraska-Lincoln, jbrand1@unl.edu

See next page for additional authors

Follow this and additional works at: https://digitalcommons.unl.edu/physicsdowben

Part of the Physics Commons

Robertson, B. W.; Adenwalla, Shireen; Harken, A.; Welsch, P.; Brand, Jennifer I.; Dowben, Peter A.; and Claassen, J.P., "A class of boron-rich solid-state neutron detectors" (2002). Peter Dowben Publications. 21.

https://digitalcommons.unl.edu/physicsdowben/21

This Article is brought to you for free and open access by the Research Papers in Physics and Astronomy at DigitalCommons@University of Nebraska - Lincoln. It has been accepted for inclusion in Peter Dowben Publications by an authorized administrator of DigitalCommons@University of Nebraska - Lincoln. 


\section{Authors}

B. W. Robertson, Shireen Adenwalla, A. Harken, P. Welsch, Jennifer I. Brand, Peter A. Dowben, and J.P. Claassen 


\title{
A class of boron-rich solid-state neutron detectors
}

\author{
B. W. Robertson, , ${ }^{\text {a) }}$ S. Adenwalla, A. Harken, P. Welsch, J. I. Brand, and P. A. Dowben \\ Departments of Mechanical Engineering and of Physics and Astronomy, \\ and Center for Materials Research and Analysis, University of Nebraska-Lincoln, Lincoln, Nebraska 68588
}

J. P. Claassen

Veterans Administration Medical Center, Omaha, Nebraska 68105

(Received 2 January 2002; accepted for publication 13 March 2001)

Real-time solid-state neutron detectors have been fabricated from semiconducting boron-carbon alloys, deposited by plasma-enhanced chemical vapor deposition. Single neutrons were detected and signals induced by gamma rays were determined to be insignificant. The source gas closo-1,2-dicarbadodecaborane (ortho-carborane) was used to fabricate the boron-carbon alloys with only the natural isotopic abundance of ${ }^{10} \mathrm{~B}$. Devices made of thicker boron-carbon alloy layers enriched in ${ }^{10} \mathrm{~B}$ could lead to increased detection efficiency and active diodes could use the inherent micron scale spatial resolution, increasing the range of possible applications. (C) 2002 American Institute of Physics. [DOI: 10.1063/1.1477942]

There are really only four elements suitable for forming solid-state semiconductor neutron detectors- $\mathrm{B}, \mathrm{Cd}, \mathrm{Gd}$, and Li. Lithium semiconductors exist $\left(\mathrm{LiInS}_{2},{ }^{1} \mathrm{LiInSe}_{2},{ }^{2}\right.$ and $\mathrm{LiZnP})^{3}$ but are difficult to fabricate reliably into devices and are very difficult materials with which to work. Gd conversion-layer-based $\mathrm{Si}$ diodes have been fabricated and proposed for neutron detection, ${ }^{4}$ but are unlikely to be particularly stable. Cadmium zinc telluride has yielded thermal neutron detection ${ }^{5}$ and the $\mathrm{Cd}$ neutron capture cross section is high, but the neutron capture produces such high energy $\gamma$-rays $(>0.5 \mathrm{MeV})$ that the detectors must be large in order to detect these $\gamma$-rays efficiently.

Boron absorbs neutrons efficiently and should yield an excellent solid-state detector if a suitable semiconductor material is found. Recently, a very robust, structurally forgiving boron-rich semiconductor-boron carbide prepared by chemical vapor deposition (CVD) methods-has successfully been used in heterojunction diodes, ${ }^{6-10}$ homojunction diodes, ${ }^{11}$ transistors, ${ }^{12}$ and tunnel diodes. ${ }^{11,13,14}$ Here we demonstrate that this semiconductor yields single neutron detection and forms the basis for a whole class of solid-state neutron detectors.

The potential of boron-rich semiconductors as solid-state neutron detectors has received serious consideration. ${ }^{15,16}$ Boron phosphide (BP) heterojunction diodes with silicon ${ }^{15,16}$ were successfully tested as alpha radiation detectors, but failed to work as neutron detectors. Boron carbide $\left(\mathrm{B}_{4} \mathrm{C}\right)$ was successfully used as a neutron detector based upon resistivity changes resulting from increased lithium doping, ${ }^{17}$ as were (111) ${ }^{10} \mathrm{BP}$ wafers. ${ }^{16}$ Lithium is a result of ${ }^{10} \mathrm{~B}(n, \alpha){ }^{7} \mathrm{Li}$ neutron capture reactions

$$
\begin{aligned}
&{ }^{10} \mathrm{~B}+n \rightarrow \operatorname{Li}(0.84 \mathrm{MeV})+{ }^{4} \mathrm{He}(1.47 \mathrm{MeV}) \\
&+\gamma(0.48 \mathrm{MeV}) \\
&{ }^{10} \mathrm{~B}+n \rightarrow{ }^{7} \operatorname{Li}(1.02 \mathrm{MeV})+{ }^{4} \mathrm{He}(1.78 \mathrm{MeV})
\end{aligned}
$$

that have $94 \%$ and $6 \%$ probability, respectively, and yield the large kinetic energies listed in parentheses. ${ }^{18}$ Boron has also been considered for conversion coatings with silicon (Ref. 19) and GaAs (Ref. 20) diodes, but the attainable efficiencies are low $(<5 \%)$ because of the limited range of the ${ }^{7} \mathrm{Li}$ and ${ }^{4} \mathrm{He}$ ions in any coating. ${ }^{20}$

For the heterojunction diode used in the present work, boron carbide films with composition near $\mathrm{B}_{5} \mathrm{C}$ were deposited on $n$-type $\mathrm{Si}(111)$ (resistivity $30 \mathrm{ohm} \mathrm{cm}$ ) in a custom designed parallel plate $13.56 \mathrm{MHz}$ rf plasma-enhanced CVD reactor. ${ }^{10}$ The $\mathrm{Si}(111)$ substrate surfaces were prepared by $\mathrm{Ar}^{+}$ion sputtering in the plasma reactor. Closo-1,2dicarbadodecaborane (ortho-carborane, $\mathrm{C}_{2} \mathrm{~B}_{10} \mathrm{H}_{12}$ ) was the single molecular source of $\mathrm{B}$ and $\mathrm{C}$ for growing the boron carbide.

The current-voltage $(I-V)$ curve of the particular diode used in this work is shown in Fig. 1. The boron carbide layer was $276 \pm 5 \mathrm{~nm}$ thick, as measured by grazing incidence $\mathrm{X}$-ray reflectivity. At the reverse bias of $18 \mathrm{~V}$ applied during neutron detection, the diode leakage current was $\sim 0.16 \mu \mathrm{A}$.

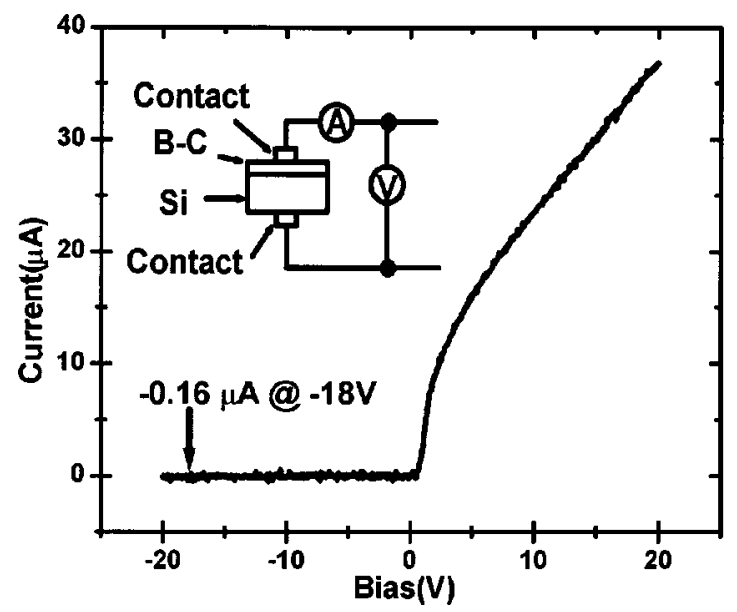

FIG. 1. $I-V$ curve of the $\mathrm{B}-\mathrm{C} / n-\mathrm{Si}$ diode used as the neutron detector, and, inset, the schematic diode geometry. Note the low leakage current. The arrow indicates the reverse bias used in neutron detection.

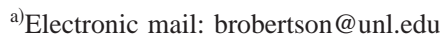




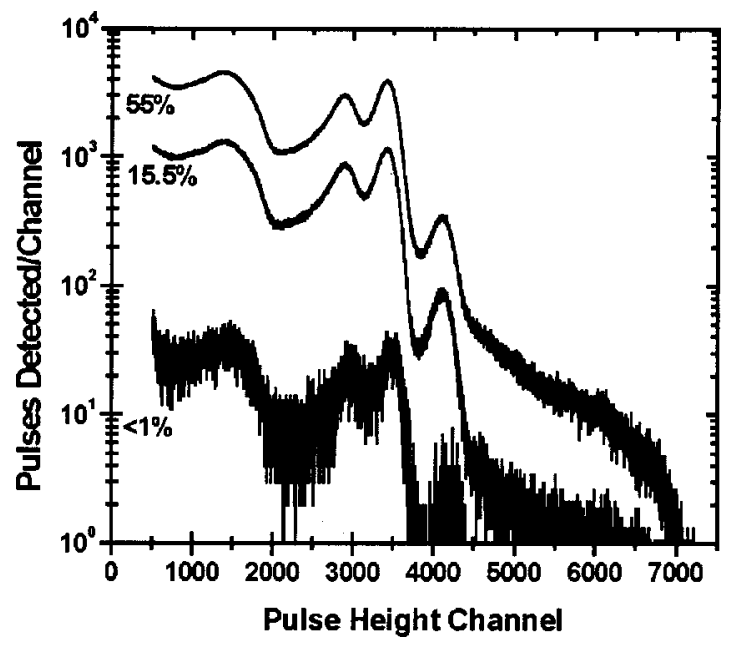

FIG. 2. Pulse height spectra (above the electronic noise) detected at $<1 \%$, $15.5 \%$, and $55 \%$ reactor power. The four peaks are attributable to neutron${ }^{10} \mathrm{~B}$ capture reaction products.

Assuming a band gap of 0.5 to $1 \mathrm{eV}$ in the semiconducting boron carbon alloy, ${ }^{6,21}$ the highly energetic $\mathrm{Li}$ and $\mathrm{He}$ ions should produce at least $10^{5}$ electron-hole pairs per neutron capture. A suitable bias applied to the diode resulted in a depletion region whose electric field enabled substantial charge collection before the electrons and holes recombined.

The heterojunction diode had a detection area $\sim 1 \mathrm{~mm}^{2}$ and was wired in the "mesa" geometry shown inset in Fig. 1. The neutron source was a $20 \mathrm{~kW}$ TRIGA (training, research, isotopes, general atomic) reactor (Veterans Administration Medical Center, Omaha, Nebraska) with a maximum thermal neutron flux of $1.5 \times 10^{11} \mathrm{n} \mathrm{cm}^{-2} \mathrm{~s}^{-1}$, based on calculations for the fission chamber. The diode, surrounded by a grounded electrostatic shield, was connected to a charge to voltage preamplifier (Amptek, model A250) and pulse counting electronics (Canberra, Digital Signal Processor model 9600) and inserted beside the reactor core in a location usually employed for neutron activation of materials. During neutron detection, a $6 \mathrm{~m}$ long triaxial cable connected the diode and preamplifier and so the associated electrical noise was not optimal. The digitized preamplifier output was processed using a digital trapezoidal filter with rise and fall times of 0.4 and a $0.1 \mu$ s flat top that responds essentially only to signals occurring on a sub- $\mu$ s time scale.

Figure 2 contains pulse height spectra, truncated to exclude most electronic noise pulses, for $<1 \%, 15.5 \%$, and $55 \%$ of maximum, as measured by the fission detector. The peak positions and all other aspects of the shape of the spectra are constant for reactor powers from $\sim 0.4 \%$ to $92 \%$, i.e., over more than 2 orders of magnitude of neutron flux. A simple momentum conservation calculation for the ${ }^{10} \mathrm{~B}(n, \alpha){ }^{7} \mathrm{Li}$ reaction indicates that the directions of the $\mathrm{Li}$ and $\mathrm{He}$ ions are close to $180^{\circ}$ apart. The range of each ion is a few $\mu \mathrm{m}$ in solid materials, comparable with our measurements of depletion depth. Therefore, either ion could escape from the thin B-C layer and the depletion regions without depositing a significant fraction of its kinetic energy in the creation of detectable electron-hole pairs. Thus, slight undercounting of captured neutrons and significant tailing on the left (lower energy) side of each spectral peak are entirely expected; both should be reduced when modified diodes with Downloaded 05 Sep 2006 to 129.93.16.206. Redistribution subject

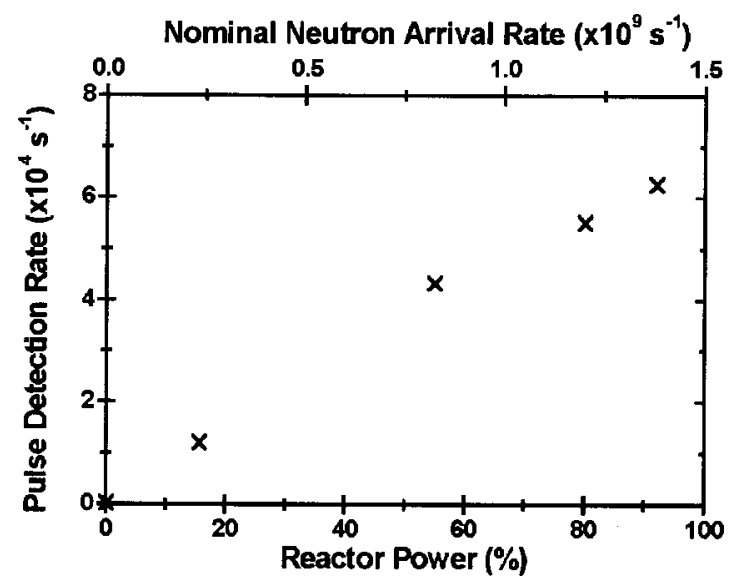

FIG. 3. Total numbers of neutrons detected, above electronic noise and in the pulse height data channels shown in Fig. 2, as a function of reactor power (and nominal neutron flux).

thicker B-C layers are used in order to increase the neutron detection efficiency.

We conclude that the data in Fig. 2 correspond to realtime detection of individual neutrons, but not fast electrons, protons, ions or $\gamma$-rays, for the following reasons. Fast electrons, protons, and ions were prevented from reaching the detector by the nature of the diode mounting and shield. Extremely low $\gamma$-ray sensitivity is expected for such a thin, low atomic-number device and no significant increase in count rate above noise was detected when the diode was bombarded by $661 \mathrm{keV} \gamma$-rays from a $38 \mathrm{mCi}{ }^{137} \mathrm{Cs}$ source only $\sim 5 \mathrm{~cm}$ from the diode. In addition, the constancy of spectral shapes in Fig. 2 over such a wide range of detection rates implies that the spectral features do not contain radiation-generated "pulse pile-up" artifacts, that could arise if the arrival rate of these pulses were too high.

Neutron-generated pulses of up to a few tens of $\mathrm{mV}$ were measured at the output of the preamplifier as a result of the $1 \mathrm{pF}$ charge-to-voltage conversion response of the preamplifier, implying that $\sim 2 \times 10^{5}$ electron-hole pairs created following the ${ }^{10} \mathrm{~B}(n, \alpha){ }^{7} \mathrm{Li}$ reaction were collected in some cases.

Total neutron detection rates (Fig. 3) were calculated by integrating the pulse height spectra over all pulse heights above channel 500 (Fig. 2), after subtracting the pulse height spectrum obtained at zero reactor power. From $\sim 0.4$ to at least $55 \%$ reactor power, these detection rates scale linearly with power and hence with neutron flux incident on the detection area.

The detection efficiency for an ideal $276 \mathrm{~nm}$ thick B-C detector is $1.3 \times 10^{-3}$, based on the following assumptions: the ${ }^{10} \mathrm{~B}$ proportion of $\mathrm{B}$ in this film is the natural $19.8 \%$ isotopic abundance; the $\mathrm{B}$ to $\mathrm{C}$ ratio is the same as in orthocarborane; the cross section for neutron capture by ${ }^{10} \mathrm{~B}$ is 2125 barns (that of a neutron with $1 \AA$ wavelength); and the detected charge pulses include all electron-hole pairs that could result from neutron capture by ${ }^{10} \mathrm{~B}$. The neutron detection efficiency determined from the data in Fig. 3 is $\sim 5$ $\times 10^{-5}$, for the correlation between reactor power and nominal incident neutron flux indicated. From additional experiments at a beam port of a second TRIGA reactor (Kansas State University), made with more accurate measures of neuto AlP license or copyright, see http://apl.aip.org/apl/copyright.jsp 
tron flux and with a lower noise $\sim 12 \mathrm{~cm}$ diode to preamplifier connection, the efficiency was found to be at least $\sim 24 \%$ of ideal, or $\sim 3.2 \times 10^{-4}$. The difference between measured and ideal efficiencies is primarily attributable to uncertainty in the neutron flux calibration and in the energy distribution of the neutrons (and so in the effective capture cross section). Undercounting because of incomplete collection of the energy of products of the ${ }^{10} \mathrm{~B}(n, \alpha)^{7} \mathrm{Li}$ reactions, as discussed herein, has a slight effect, that will further be reduced by changes that improve capture efficiency and reduce electronic system noise (now equivalent to $<10^{4}$ electrons).

We find the $\mathrm{B}-\mathrm{C} / n-\mathrm{Si}$ diodes are quite radiation hard: even a thermal neutron fluence of $\sim 1 \times 10^{15} \mathrm{n} \mathrm{cm}^{-2}$ caused $<5$ times increase in leakage currents measured after irradiation; and no significant additional increase was observed during exposure to the high radiation field within the reactor.

Given that diodes can be made with B-C layers 50 to $100 \mu \mathrm{m}$ thick and with depletion layers several $\mu \mathrm{m}$ thick, ${ }^{7}$ the single (thermal) neutron detection efficiencies are conservatively expected to reach $80 \%$ in future devices made with $100 \mu \mathrm{m}$ thick B-C layers containing the ${ }^{10} \mathrm{~B}$ enrichment $(>80 \%)$ expected from available enriched carboranes. Such devices should simultaneously have low $\gamma$-ray detection efficiency-under $1 \%$ or $0.01 \%$ for all $\gamma$-ray energies above $100 \mathrm{keV}$ or $500 \mathrm{keV}$, respectively_but high neutron detection efficiencies, assured by the use of ${ }^{10} \mathrm{~B}$ as the dominant atomic species. The enormous effective gain we determined for neutron capture by ${ }^{10} \mathrm{~B}$ in the $\mathrm{B}-\mathrm{C}$ semiconducting layer of the detector at only $18 \mathrm{~V}$ bias is essentially noise free and is comparable with the gain of intensifiers and photomultipliers used in scintillation-based detectors and imagers, but is attained without their bulk, mass, or power requirements.

Efficient, thin $\mathrm{B}-\mathrm{C}$ diodes could provide high-resolution neutron time-of-flight measurements. Used with $\mathrm{B}-\mathrm{C}$ based high-temperature electronics, ${ }^{7,10}$ the $\mathrm{B}-\mathrm{C}$ based neutron detection systems are expected to be particularly applicable in harsh environments since the $\mathrm{B}-\mathrm{C} / n$-Si diodes are radiation hard and conventional $\mathrm{B}_{4} \mathrm{C}$ is a mechanically hard, refractory ceramic. The $\mathrm{B}-\mathrm{C}$ devices may even be fabricated on metal substrates to form successful diodes and transistors ${ }^{7}$ and fabricated to provide position resolution, in principle, below a few $\mu \mathrm{m} .{ }^{8}$ The latter suggests the possibility, too, of array detectors and imagers. These, and detectors that use charge division, could provide position sensors for scattering experiments.
In summary, we have clearly demonstrated the singleneutron detection potential of a class of neutron detectors based on semiconducting boron-carbon semiconductors (near $\mathrm{B}_{5} \mathrm{C}$ ). Isotopically enriched in ${ }^{10} \mathrm{~B}$, these have the potential to simultaneously exceed the limits of other B-rich semiconductor detectors, including $\mathrm{B}-\mathrm{P}$, and to avoid the limitations of currently recognized detectors.

This work was supported by the Nebraska Research Initiative and the University of Nebraska. The authors are grateful to the Veterans Administration Medical Center, Omaha, and to M. Whaley, Kansas State University, for generous access to the TRIGA reactors.

${ }^{1}$ T. Kamijoh and K. Kuriyama, J. Appl. Phys. 51, 1827 (1980)

${ }^{2}$ C. J. Smith and C. W. Low, J. Appl. Phys. 66, 5102 (1989).

${ }^{3}$ R. Bacewicz and T. F. Ciszelk, Appl. Phys. Lett. 52, 1150 (1988).

${ }^{4}$ A. Mireshghi, G. Cho, J. Drewery, T. Jing, S. N. Kaplan, V. PerezMendez, and D. Wildermuth, IEEE Trans. Nucl. Sci. 39, 635 (1992); A. Mireshghi, G. Cho, J. S. Drewery, W. S. Hong, T. Jing, S. N. Kaplan, and V. Perez-Mendez, ibid. 41, 915 (1992).

${ }^{5}$ D. S. McGregor, J. T. Lindsay, and R. W. Olsen, Nucl. Instrum. Methods Phys. Res. A 381, 498 (1996).

${ }^{6}$ S. Lee, J. Mazurowski, G. Ramseyer, and P. A. Dowben, J. Appl. Phys. 72, 4925 (1992).

${ }^{7}$ S. Lee and P. A. Dowben, Appl. Phys. A: Solids Surf. 58, 223 (1994).

${ }^{8}$ D. Byun, S.-D. Hwang, P. A. Dowben, F. K. Perkins, F. Filips, and N. J. Ianno, Appl. Phys. Lett. 64, 1968 (1994).

${ }^{9}$ A. A. Ahmad, N. J. Ianno, S.-D. Hwang, and P. A. Dowben, Thin Solid Films 335, 174 (1998).

${ }^{10}$ S. Adenwalla, P. Welsch, A. Harken, J. I. Brand, A. Sezer, and B. W. Robertson, Appl. Phys. Lett. 79, 4357 (2001).

${ }^{11}$ S.-D. Hwang, K. Yang, P. A. Dowben, A. A. Ahmad, N. J. Ianno, J. Z. Li, J. Y. Lin, H. X. Jiang, and D. N. McIlroy, Appl. Phys. Lett. 70, 1028 (1997).

${ }^{12}$ S.-D. Hwang, D. Byun, N. J. Ianno, P. A. Dowben, and H. R. Kim, Appl. Phys. Lett. 68, 1495 (1996).

${ }^{13}$ S.-D. Hwang, N. B. Remmes, P. A. Dowben, and D. N. Mcllroy, J. Vac. Sci. Technol. B 14, 2957 (1996).

${ }^{14}$ S.-D. Hwang, N. Remmes, P. A. Dowben, and D. N. McIlroy, J. Vac. Sci. Technol. A 15, 854 (1997).

${ }^{15}$ J. C. Lund, F. Olschner, F. Ahmed, and K. S. Shah, Mater. Res. Soc. Symp. Proc. 162, 601 (1990).

${ }^{16}$ Y. Kumashiro, K. Kudo, K. Matsumoto, Y. Okada, and T. Koshiro, J. Less-Common Met. 143, 71 (1988).

${ }^{17}$ Y. A. Bykovskii, K. N. Zaitsev, P. D. Kervalishvili, I. N. Nikolaev, A. A. Portnov, and S. O. Shalamberidze, Tech. Phys. Lett. 19, 457 (1993).

${ }^{18}$ G. F. Knoll, Radiation Detection and Measurement (Wiley, New York, 1979).

${ }^{19}$ H. Kitaguchi, H. Miyai, S. Izumi, and A. Kaihara, IEEE Trans. Nucl. Sci. 43, 1846 (1996).

${ }^{20}$ D. S. McGregor, J. T. Lindsay, C. C. Brannon, and R. W. Olson, IEEE Trans. Nucl. Sci. 43, 1357 (1996).

${ }^{21}$ A. A. Ahmad, N. J. Ianno, P. G. Snyder, D. Welipitiya, D. Byun, and P. A. Dowben, J. Appl. Phys. 79, 8643 (1996). 